\title{
Impact of seasonal climatic variability on rice yield in Bangladesh
}

\section{JAIONTO KARMOKAR*, M. AMINUL ISLAM, M. RAKIB HASSAN and M.M.BILLAH}

Department of Computer Science and Mathematics, Bangladesh Agricultural University, Mymensingh-2202, Bangladesh. *Corresponding author: jaiontoj@gmail.com

\begin{abstract}
In Bangladesh, $75 \%$ of the total cultivable area is under rice cultivation producing 25 million tons of rice and plays a vital role in the country's GDP. The climatic variability is playing an important role in affecting the rice production. In this study, the impact of climatic variability (average maximum temperature (aMaxTemp), average minimum temperature (aMinTemp) and average rainfall (aRainfall)) on rice yield was determined in two different regions (northern and southern) of Bangladesh. The variability of rice yield and climate factors was determined by using the Ordinary Least Square (OLS) method. The data was analyzed over the 44-years period (1971 to 2014) in order to estimate the magnitude of these fluctuations statistically and graphically. We observed that the climate variables had significant effect on rice yield that varies among three rice crops (e.g., Aus, Aman, and Boro rice). We observed that, aMaxTemp has positive effects for Aus and Aman rice yield but negative effect on Boro rice yield. On the other hand, aMinTemp has negative effects on Aus and Aman rice yield but has positive effect on Boro rice yield. The aRainfall has a positive relationship with all rice yields in both the regions.
\end{abstract}

Keywords: Rice yield, climate variability, test of normality, ordinary least square.

Rice (Oryza sativa L.) is the most important cereal crop which is a staple food around 158 million people of Bangladesh and more than half of the world's population (Ma et al., 2007; Fageria, 2007). The seasonal climatic variability is severely decreasing the yield of rice and may frighten the food safety of the increasing population. Approximately $90 \%$ of the people of Bangladesh consume $410 \mathrm{~g}$ of rice head ${ }^{-1} \mathrm{day}^{-1}$. Around $85 \%$ of the rural people are directly or indirectly involved in agriculture and they play an important role by contributing to $16.33 \%$ of GDP in Bangladesh (Bangladesh Bank, 2014; GOB, 2017). The variability in temperature and rainfall have increased and unpredictable, and the occurrence of climate related extreme events such as floods, droughts, heat waves, and cyclones are anticipated to increase in the future (FAO, 2006; IPCC, 2007; Yu et al., 2010; Bal and Minhas, 2017). Country is predicted to experience an increase in daily average temperature of $1^{\circ} \mathrm{C}$ by 2030 and of $1.4{ }^{\circ} \mathrm{C}$ by 2050 (FAO, 2006; IPCC, 2007). Rainfall is showing irregular distribution, which has adverse effects on rice yields (Alauddin and Hossain, 2001; GOB and UNDP, 2009). It is observed that the variation of rainfall has more impact than the change in temperature on crop production (Rivington et al., 2011). To mitigate the impact of rainfall, timely irrigation can contribute to increased crop yield (Adams et al., 1995).

In recent times, some studies have investigated the effects of weather variation on agronomic production of rice in developing countries (Haim et al., 2008; Deressa and Hassan, 2009; Bhuvaneswari et al., 2014; Karmokar et al., 2019). To estimate the effects of climate variability on rice production of Bangladesh, the investigators (Karim et al., 1996; Basak et al., 2010; Vysakh et al., 2017) used CERESRice model and the DASSAT model. Sandhu et al. (2013) analyzed 12 years' data to ascertain the impact of meteorological parameters in seasonal variability on rice production in central Punjab, India. Also the regression models over historical data to find a relationship between climate variables and crop yield (Isik and Devadoss, 2006; Mallick et al., 2007; Joshi et al., 2011; Sarker et al., 2012; Dari et al., 2017; Karmokar et al., 2019). But they didn't check the data variability like the area of rice cultivation, regional variations and rice yield during the year of 19712014. The main objective of our study is to estimate the effects of climate parameters on rice yield of growing seasons. For our study we have considerd northern and southern regions of Bangladesh because these two regions cultivate Aus, Aman and Boro rice.

\section{MATERIALS AND METHODS}

The historical rice yields were collected for the period of 1971 to 2014 for both northern and southern regions of Bangladesh. Data related to weather variables were collected from the Meteorological Observatory, Bangladesh Meteorological Department (BMD) and the locations of the 

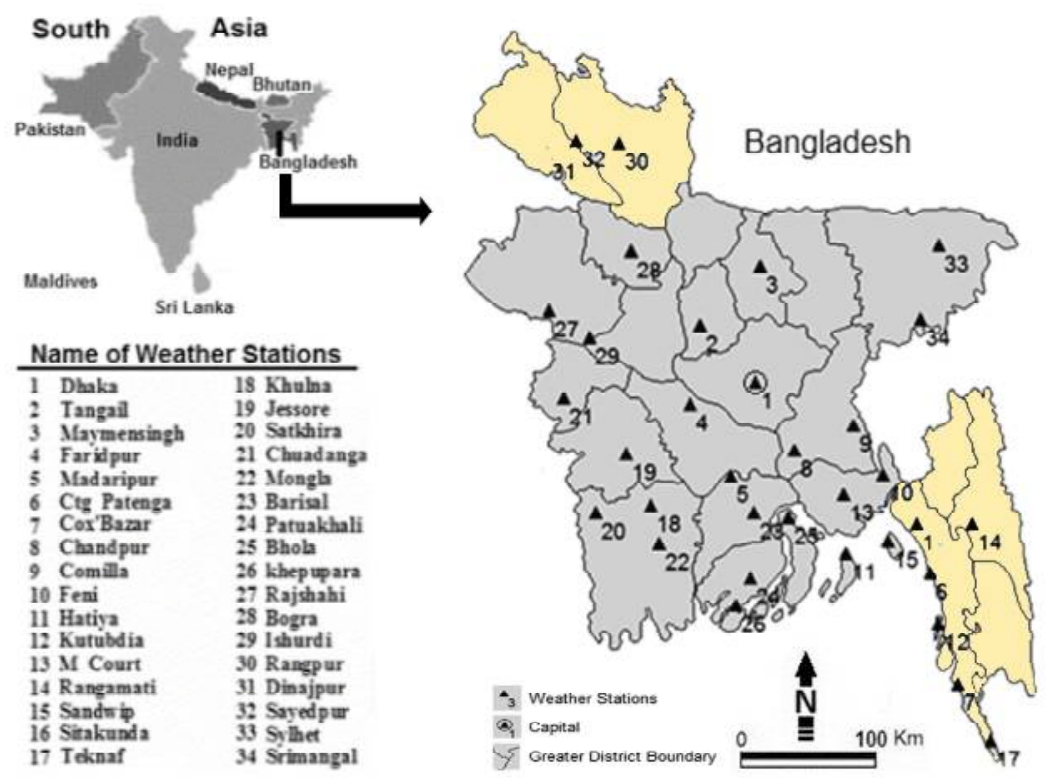

Fig.1: Study area with location of meteorological stations of BMD

weather stations are shown in Fig. 1. Also Rice production and cultivated land area data was collected from Bangladesh Rice Research Institute (BRRI). The time series of measurements was used during analysis and we considered four stations: Dinajpur, Rangpur, Chittagong, and Rangamati. The missing data was interpreted by calculating the average value of the same month data.

Tests of normality of dependent variables are shown in Table 1. The model was calibrated and validated with experimental data of each crop. The daily historical weather data were analyzed to determine climatic variability trends by regression model. To analyze possible effects of climatic factors on rice yield by identifying the incremental variations to climatic parameters and applying these changes uniformly to baseline climate was employed in the present study. Since the samples of this study are less than 50 years, we used Kolmogorov-Smirnov and Shapiro-Wilk test to determine the distribution of rice yield of three growing seasons in Bangladesh.

Since the p-value (significance) in KolmogorovSmirnov and Shapiro-Wilk test the yield of Aus and Boro in both regions was higher than 0.05 , so that they followed the normal distribution. But the yield of Aman in both regions was less than 0.05 , so we checked the distribution using $\mathrm{z}-$ value of Skewness and Kurtosis which is shown in Table 2. Since the z-value between -1.96 to +1.96 than the yield of Aman followed the normal distribution. Therefore, we used Ordinary Least Square (OLS) method for the estimation of the coefficient of determinants. The relationship between climate factors and rice yield was not always linear since the increase of temperature or rainfall would be advantageous for rice yield at a limited effect over this factors. The OLS equation is estimated by taking $\mathrm{Ln}$ in both sides (Chung et al., 2015). Therefore, the regression models are employed on the basis of distribution of the yields (dependent variables) for three rice variety as following:

$\ln Y_{r t}=\delta_{0}+\delta_{1} \ln ($ aMinTemp $)+\delta_{2} \ln ($ aMaxTemp $)+\delta_{3} \ln ($ aRainfall $)+E_{t}$

Where $\mathrm{Y}_{\mathrm{rt}}$ is yield of rice (ton acre ${ }^{-1}$ ) of three growing seasons, aMinTemp is the average minimum temperature $\left({ }^{\circ} \mathrm{C}\right)$ by seasons, aMaxTemp is the average maximum temperature $\left({ }^{\circ} \mathrm{C}\right)$ by seasons, aRainfall is the average rainfall $(\mathrm{mm})$ by seasons,$\in_{\mathrm{t}}$ is the error term and $\mathrm{t}$ is the time (year).

\section{RESULTS AND DISCUSSION}

The summary statistics for all the data in northern region and southern region are presented in Table 3. This table also illustrates the fundamental climate characteristics during three rice growing seasons in Bangladesh. But, these descriptive statistics do not provide any evidence of variability in climate that impacted on rice production. In order to provide the quantitative justification for climate variability affected on rice yield during different growing seasons, the OLS method was used. This method is employed to identify the effects of climate variation (i.e., aMaxTemp, aMinTemp, aRainfall) on the seasonal Aus rice model, Aman rice model and Boro rice model results are presented in Table 
Table 1: Tests of normality of dependent variables

\begin{tabular}{|c|c|c|c|c|c|c|c|c|}
\hline \multirow[t]{3}{*}{ Variables } & \multicolumn{4}{|c|}{ Northern region } & \multicolumn{4}{|c|}{ Southern region } \\
\hline & \multicolumn{2}{|c|}{ Kolmogorov-Smirnov } & \multicolumn{2}{|c|}{ Shapiro-Wilk } & \multicolumn{2}{|c|}{ Kolmogorov-Smirnov } & \multicolumn{2}{|c|}{ Shapiro-Wilk } \\
\hline & Statistic & Sig. & Statistic & Sig. & Statistic & Sig. & Statistic & Sig. \\
\hline Yield_Aus & 0.08 & 0.20 & 0.97 & 0.36 & 0.09 & 0.20 & 0.95 & 0.08 \\
\hline Yield_Aman & 0.15 & 0.02 & 0.92 & 0.01 & 0.17 & 0.00 & 0.88 & 0.00 \\
\hline Yield_Boro & 0.11 & 0.20 & 0.95 & 0.05 & 0.08 & 0.20 & 0.97 & 0.22 \\
\hline
\end{tabular}

Table 2: Tests of normality using z-values

\begin{tabular}{lllllll}
\hline Cases & \multicolumn{3}{c}{ Skewness } & \multicolumn{2}{c}{ Kurtosis } \\
\cline { 2 - 7 } & Measure & Std. Error & z-value & Measure & Std. Error & $\dot{z}$-value \\
\hline Northern Aman_Yield & 0.56 & 0.36 & 1.55 & -0.29 & 0.70 & -0.41 \\
Southern Aman_Yield & 0.46 & 0.36 & 1.27 & -1.31 & 0.70 & -1.87 \\
\hline
\end{tabular}

Table 3: Summary statistic of the Northern region and Southern region of Bangladesh

\begin{tabular}{|c|c|c|c|c|c|c|c|c|c|c|}
\hline \multicolumn{11}{|c|}{ Variables } \\
\hline \multirow[t]{2}{*}{ Regions } & \multirow{2}{*}{$\begin{array}{l}\text { Selected } \\
\text { Stations }\end{array}$} & \multirow{2}{*}{$\begin{array}{l}\text { Rice } \\
\text { Varaity } \\
\end{array}$} & \multicolumn{2}{|c|}{$\operatorname{aMaxTemp}\left({ }^{0} \mathrm{C}\right)$} & \multicolumn{2}{|c|}{ aMinTemp $\left({ }^{0} \mathrm{C}\right)$} & \multicolumn{2}{|c|}{ aRainfall (mm) } & \multicolumn{2}{|c|}{ Yield (ton/acre) } \\
\hline & & & Mean & Std & Mean & Std & Mean & Std & Mean & Std \\
\hline \multirow{3}{*}{$\begin{array}{l}\text { Northern } \\
\text { region }\end{array}$} & Dinajpur & Aus & 31.95 & 1.49 & 23.18 & 0.97 & 255.65 & 63.51 & 0.44 & 0.08 \\
\hline & Rangpur & Aman & 29.99 & 1.42 & 21.63 & 0.52 & 216.52 & 66.37 & 0.67 & 0.15 \\
\hline & & Boro & 29.54 & 1.83 & 18.48 & 0.95 & 127.99 & 41.55 & 1.16 & 0.20 \\
\hline \multirow{3}{*}{$\begin{array}{l}\text { Southern } \\
\text { region }\end{array}$} & Chittagong & Aus & 31.63 & 1.29 & 23.80 & 0.66 & 354.10 & 66.27 & 0.62 & 0.14 \\
\hline & Rangamati & Aman & 30.15 & 1.31 & 22.45 & 0.41 & 268.93 & 63.63 & 0.77 & 0.18 \\
\hline & & Boro & 30.35 & 1.57 & 20.38 & 0.69 & 178.96 & 46.80 & 1.09 & 0.09 \\
\hline
\end{tabular}

4, Table 5 and Table 6, respectively. Graphs are provided that demonstrate the variations of climate with comparison of rice yields in these period. The effect of climate factors on three growing rice seasons are presented in Fig. 2 and Fig. 3 , respectively.

The OLS method was applied to provide the quantitative justification and to establish the relationship between climate factors and rice yield in three different growing seasons. The significance of three models are shown by F-value which indicated that for this data, the overall regression models were good. The R-square values show the variation of rice yield with climate factors in different seasons. The variation of rice yield can be explained by climate variables involved in the model for Aus, Aman and Boro seasons are $3 \%, 4 \%$ and $19 \%$, respectively in the northern region and also $4 \%, 3 \%$ and $13 \%$, respectively in the southern region. Dubin-Watson statistics were not too low which indicates that the regression models did not suffer from serial correlation. The value of D-W statistic is an improvement in the study by Ozkan and Akcaon (2002) which indicate the problem of positive serial correlation. Multicollinearity among independent variables was shown by VIF (Variance Inflation Factor) values, which indicates that there is no multicollinearity. In addition, p-values of Breusch-Pagan Chi-Square values were more than significant level at $5 \%$, so that we accepted the null hypothesis about heteroscedasticity which means that the regression models did not suffer from the problem of heteroscedasticity. Also t-ratio of aMaxTemp and aMinTemp in both regions indicate that both aMaxTemp and aMinTemp are statistically significant.

The effects of the climate variables on Aus and Aman rice yield are presented in Table 4 and Table 5. From both the tables, we observed that, Rainfall and aMaxTemp has significantly positive impact on rice yield and aMinTemp has negative impact on rice yield of both the regions. From BRRI 2015, during the initial period of Aus rice growing, and the planting and flowering time of Aman rice yield a lot of irrigation is required. In addition, Aman is cultivated in July or August month and this month are the rainy seasons of 


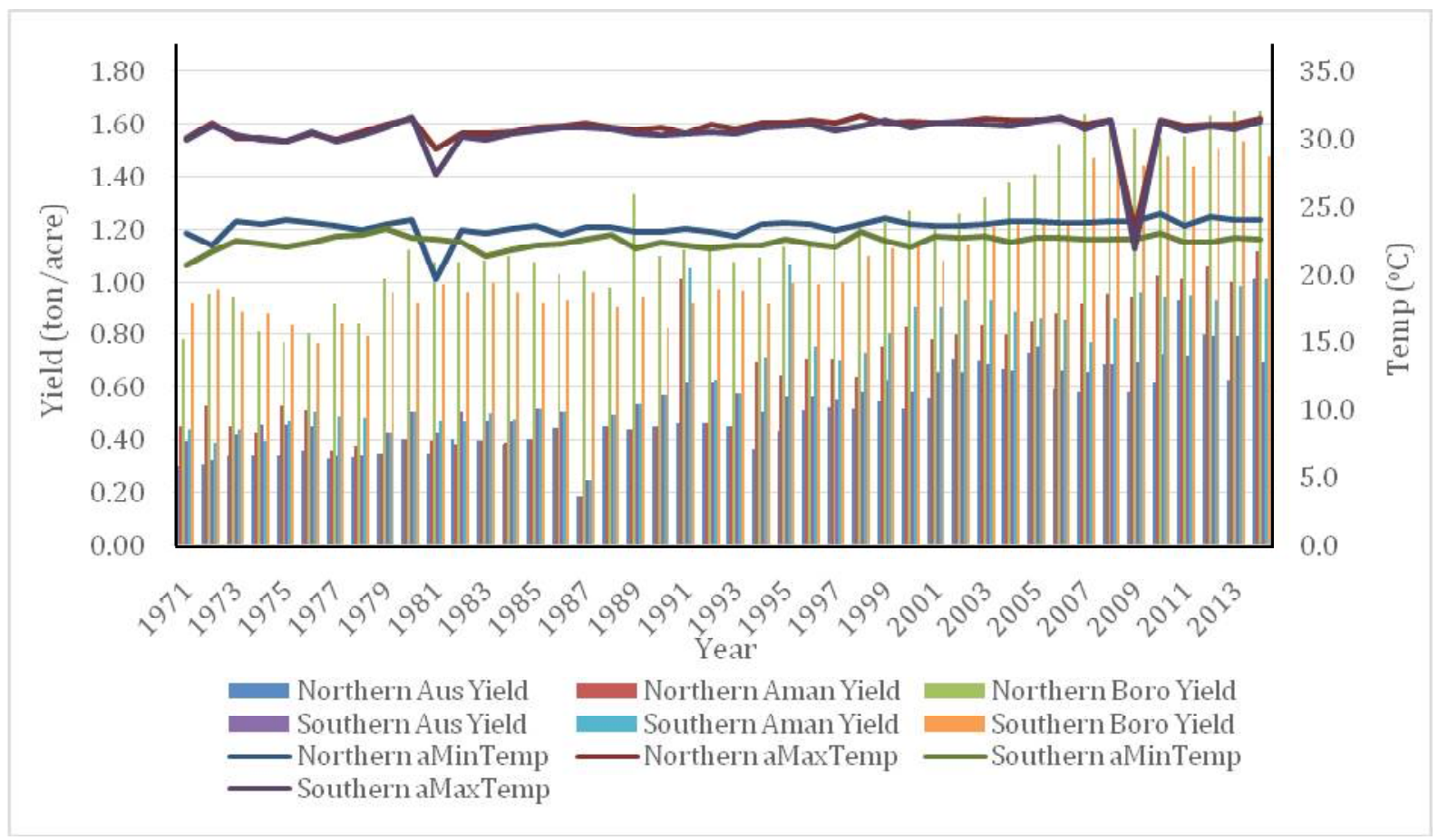

Fig. 2: Effects of annual temperature on rice yield in different seasons of both Northern and Southern region.

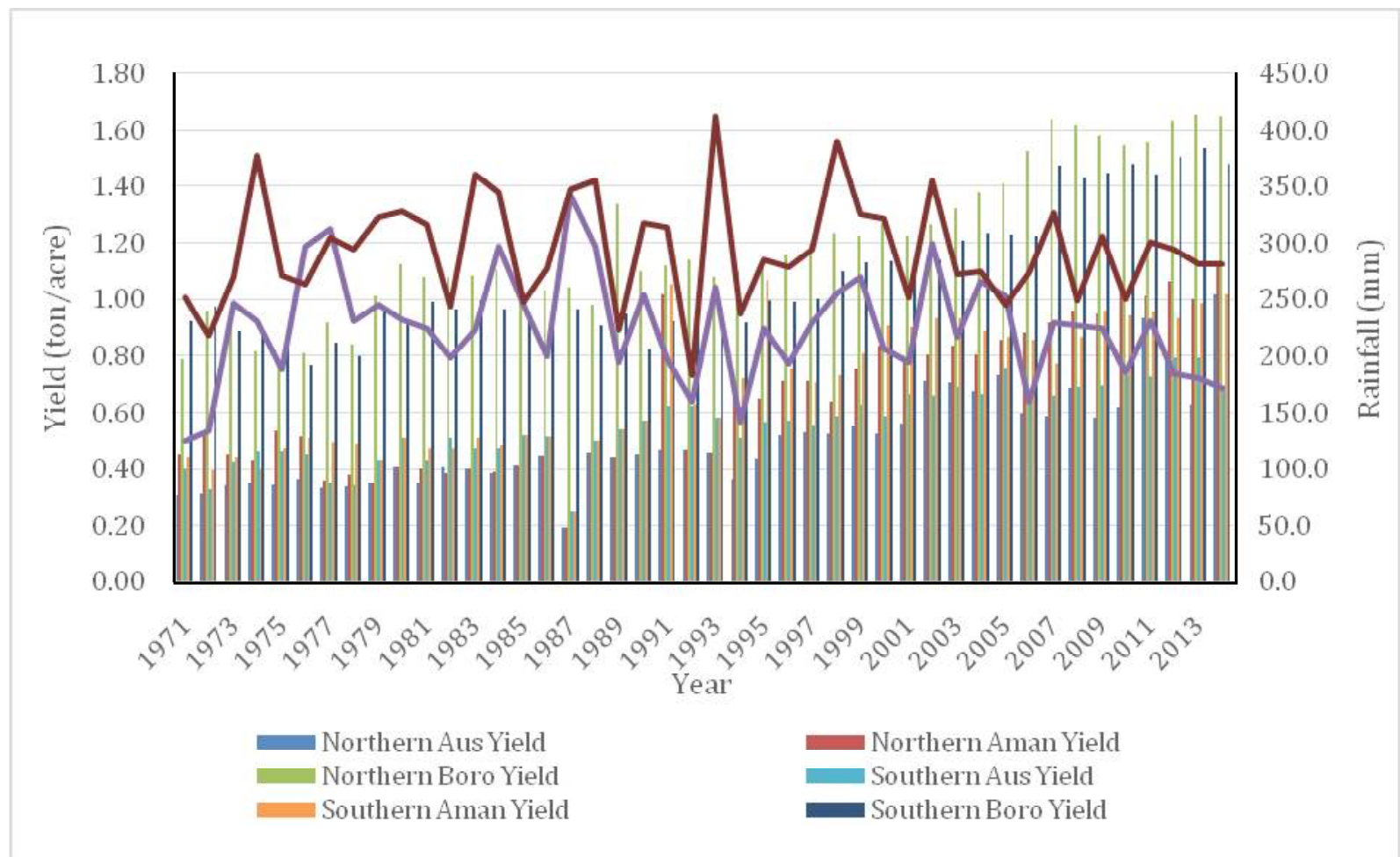

Fig. 3: Effects of annual average rainfall on rice yield in different seasons of both Northern and Southern region.

Bangladesh. This is because, aRainfall and aMaxTemp has a positive effect on Aus and Aman rice yield and only $8 \%$ of Aus rice and $5 \%$ of Aman rice are required irrigation (Ahmed, 2001).

On the other hand, for Boro rice yield (Table 6) we observed that, aRainfall and aMinTemp has positive impact and aMaxTemp has negative impact on rice yield. Because Boro rice is cultivated in December or January, and harvested in May or June month which is the dry season in Bangladesh. In this time, the temperature is not too high and rainfall is too 
Table 4: The results for the seasonal Aus rice model

\begin{tabular}{|c|c|c|c|c|c|c|c|c|}
\hline \multirow[t]{2}{*}{ Variables } & \multicolumn{4}{|c|}{ Northern region } & \multicolumn{4}{|c|}{ Southern region } \\
\hline & Coefficients & Std. Error & t-ratio & VIF & Coefficients & Std. Error & t-ratio & VIF \\
\hline Intercept & 1.76 & 5.52 & 0.32 & & 4.03 & 6.91 & 0.58 & \\
\hline Ln (aMinTemp) & -1.17 & 1.63 & -0.72 & 1.00 & -2.11 & 2.04 & -1.04 & 1.00 \\
\hline Ln (aMaxTemp) & 3.91 & 1.52 & 2.63 & 1.06 & 4.22 & 1.42 & 3.91 & 1.04 \\
\hline Ln (aRainfall) & 0.40 & 0.26 & 0.81 & 1.02 & 0.43 & 0.39 & 0.96 & 1.02 \\
\hline R-square & 0.03 & & & & 0.04 & & & \\
\hline Adjust R-square & 0.05 & & & & 0.03 & & & \\
\hline F value & 0.33 & & & & 0.58 & & & \\
\hline Dubin-Watson test & 0.06 & & & & 0.12 & & & \\
\hline Breusch-Pagan chi-square & 1.32 & & & & 1.76 & & & \\
\hline P-value of chi-square & 0.04 & & & & 0.10 & & & \\
\hline
\end{tabular}

Table 5: The results for the seasonal Aman rice model

\begin{tabular}{|c|c|c|c|c|c|c|c|c|}
\hline \multirow[t]{2}{*}{ Variables } & \multicolumn{4}{|c|}{ Northern region } & \multicolumn{4}{|c|}{ Southern region } \\
\hline & Coefficients & Std. Error & t-ratio & VIF & Coefficients & Std. Error & t-ratio & VIF \\
\hline Intercept & 2.82 & 6.56 & 0.43 & & 2.85 & 6.73 & 0.42 & \\
\hline Ln (aMinTemp) & -1.22 & 1.92 & -0.63 & 1.00 & -1.31 & 1.97 & -0.67 & 1.00 \\
\hline Ln (aMaxTemp) & 2.14 & 1.74 & 0.48 & 1.02 & 1.20 & 0.96 & 0.26 & 1.02 \\
\hline Ln (aRainfall) & 0.31 & 0.45 & 0.19 & 1.02 & 0.35 & 0.35 & 0.34 & 1.01 \\
\hline R-square & 0.04 & & & & 0.03 & & & \\
\hline Adjust R-square & 0.06 & & & & 0.05 & & & \\
\hline F value & 0.14 & & & & 0.19 & & & \\
\hline Dubin-Watson test & 0.03 & & & & 0.04 & & & \\
\hline Breusch-Pagan chi-square & 1.76 & & & & 1.32 & & & \\
\hline P-value of chi-square & 0.07 & & & & 0.06 & & & \\
\hline
\end{tabular}

Table 6: The results for the seasonal Boro rice model

\begin{tabular}{|c|c|c|c|c|c|c|c|c|}
\hline \multirow[t]{2}{*}{ Variables } & \multicolumn{4}{|c|}{ Northern region } & \multicolumn{4}{|c|}{ Southern region } \\
\hline & Coefficients & Std. Error & t-ratio & VIF & Coefficients & Std. Error & t-ratio & VIF \\
\hline Intercept & 0.99 & 1.72 & 0.58 & & 1.12 & 1.31 & 0.61 & \\
\hline Ln (aMinTemp) & 0.55 & 0.45 & 1.23 & 1.10 & 0.64 & 0.38 & 1.68 & 1.09 \\
\hline Ln (aMaxTemp) & -0.79 & 0.33 & -2.42 & 1.01 & -0.11 & 0.21 & -0.53 & 1.04 \\
\hline Ln (aRainfall) & 0.04 & 0.06 & 0.73 & 1.11 & 0.10 & 0.05 & 2.11 & 1.09 \\
\hline R-square & 0.19 & & & & 0.13 & & & \\
\hline Adjust R-square & 0.13 & & & & 0.06 & & & \\
\hline F value & 3.21 & & & & 1.95 & & & \\
\hline Dubin-Watson test & 0.45 & & & & 0.34 & & & \\
\hline Breusch-Pagan chi-square & 8.36 & & & & 5.72 & & & \\
\hline $\mathrm{P}$-value of chi-square & 0.23 & & & & 0.14 & & & \\
\hline
\end{tabular}


low in comparison with other two rice seasons. That's why rainfall has a positive impact but it is very low, $4 \%$ and $10 \%$ for northern and southern regions, respectively. So Boro rice yield requires adequate and regular irrigation (Mahmood, 1997).

\section{CONCLUSION}

The main objective of this study was to estimate the effects of climate parameters on the rice yield for Aus, Aman and Boro seasons. The relationships between rice yield and climate factors were found using Ordinary Least Square (OLS) method. From this study, we observed that the impacts of climate variables vary among rice growing seasons.In the case of Aus rice, the seasonal aMaxTemp and aRainfall was positively impacted whereas it was negatively impacted by aMinTemp on both the regions. In contrast, we observed that the rice yield in Aman season was negatively impacted by aMinTemp whereas it was positively impacted by the climate factors (i.e., aMaxTemp, aRainfall). In addition to this, the rice yield in Boro season was positively impacted by the climate factors (i.e., aMin Temp, aRainfall) whereas it was negatively impacted by the aMaxTemp in both the regions. However, the magnitude of the effects are not same. The rice models have been found to be statistically significant and the results of overall goodness are suitable in terms of $\mathrm{R}^{2}$ and $\mathrm{F}$-values. In Bangladesh, climate change is a serious issue and impacting negatively on rice cultivation. Moreover, the population of our country is raising day by day. So the demand of the era is to increase the rice production. These experimental results can be used to establish an environment for determining the impact of climate change on rice production whereas the need of other factors can be measured and applied as per requirement to have a sustainable and enhanced rice production system. In the future, divisionwise or district-wise impact of climatic parameters on rice production can be studied for more precise information.

\section{REFERENCES}

Adams, R., Fleming, R., Chang, C., McCarl, B. and Rosenzweig, C. (1995). A reassessment of the economic effects of global climate change on US agriculture. Clim. Change, 30: 146-167.

Ahmed, R. (2001). Retrospect of the Rice Economy of Bangladesh. UniversityPress Limited, Dhaka.

Alauddin, M. and Hossain, M. (2001). Environment and Agriculture in a Developing Economy: Problems and Prospects for Bangladesh. Edward Elgar, London.
Bal, S.K. and Minhas, P.S. (2017). Atmospheric Stressors: Challenges and Coping Strategies. In: "Abiotic Stress Management forResilientAgriculture”.(Eds. P.S. Minhas et al.). pp. 9-50, Springer Nature Singapore Pte.Ltd.

Basak, J.K., Ali, M.A., Islam, M.N. and Rashid, M.A. (2010). Assessment of the effect of climate change on Boro rice production in Bangladesh using DSSAT model. J. Civil Engineer., 38: 95-108.

Bangladesh Bank. (2014). Annual Report 2013-14. Dhaka, Bangladesh (www.bangladesh bank.org/).

Bhuvaneswari, K., Geethalakshmi, V., Lakshmanan, A., Anbhazhagan, R. and Sekhar, D.N.U. (2014). Climate change impact assessment and developing adaptation strategies for rice crop in western zone of Tamil Nadu. $J$. Agrometeorol., 16(1): 38-43.

BMD (Bangladesh Meteorological Department). (2015). Data collected from BMD Headquarter at Agargoan, Dhaka. (http://www.bmd.gov.bd/).

BRRI(Bangladesh Rice Research Institute). (2015). Rice Yield and Environmental Data collected from BRRI, Dhaka, Bangladesh (http://www.brri.gov.bd/).

Chung, N.T., Jintrawet, A. and Promburom, P.(2015). Impacts of seasonal climate variability on rice production in the central highlands of Vietnam. Agri. Agricultural Sci. Procedia, 83-88.

Chowdhury, I.U.A. and Khan, M.A.E. (2015). The impact of climate change on rice yield in Bangladesh: a time series analysis. Russian J. Agri. Socio-Eco. Sci., 4 (40).

Dari, B., Sihi, D., Bal, S.K. and Kunwar, S. (2017). Performance of direct-seeded rice under various dates of sowing and irrigation regimes in semi-arid region of India. Paddy Water Environ., 15: 395-401.

Deressa, T.T. and Hassan, R.M. (2009). Economic impact of climate change on crop production in Ethiopia: evidence from cross-section measures. J. African Eco., 18: 529554.

Fageria, N.K. (2007). Yield physiologyofrice.J. Plant Nutrition, 30: 843-879.

FAO (Food and Agriculture Organization) (2006). Livelihood adaptation to climate variability and changes in droughtprone areas of Bangladesh, Rome, Italy.

GOB (Government of Bangladesh) (2017). The seventh five year plan (2017-2020). 
GOB (Government of Bangladesh), and UNDP(United Nations Development Program) (2009). The Probable Impacts of Climate Change on Poverty and Economic Growth and Options of Coping with Adverse Effects of Climate Change in Bangladesh, Policy Study, Dhaka.

Haim, D., Shechter, M. and Berliner, P. (2008). Assessing the impact of climate change on representative field crops in Israel agriculture: a case study of wheat and cotton. Clim. Change, 86: 425-440.

IPCC (Intergovernmental Panel on Climate Change). (2007). Impacts, adaptation and Vulnerability: contribution of Working Group II to the fourth assessment report of the Intergovernmental Panel on ClimateChange. Cambridge University Press, Cambridge, UK.

Isik, M. and Devadoss, S. (2006). An analysis of the impact of climate change on crop yields and yield variability. App. Econ., 38: 835-844.

Joshi, N.P., Maharjan, K.L. andLuni, P.(2011). Effect of climate variables on yield of major food-crops in Nepal. $J$. Contemp. India Stud.: Space Soc., 1: 19-26.

Karim, Z., Hussain, S. and Ahmed, M. (1996). Assessing impacts of climate variations on food grain production in Bangladesh. Water Air Soil Pollut., 92: 53-62.

Karmokar, J., Billah, M.M. and Haque, M.A. (2019). Effect of temperature variation on Aman and Boro rice production of Barisal division in Bangladesh. Progressive Agri., 30(1): 95-103.

Ma, H., Chong, K. and Deng, X.W. (2007). Rice research: Past, present and future. J. Integrative Plant Biol., 49: 729730 .

Mahmood, R. (1997). Impacts of air temperature variations on the Boro rice phenology in Bangladesh: implications for irrigation requirements. Agric. For. Meteorol., 84: 233247.
Mallick, K., Mukherjee, J., Bal, S.K., Bhalla, S.S. and Hundal, S.S. (2007). Real time rice yield forecasting over central Punjab region using crop weather regression model. $J$. Agrometeorol., 9(2): 158-166.

Ozkan, B. and Akcaon, H. (2002). Impacts of climate factors on yields for selected crops in Southern Turkey. Mitig. Adapt. Strat. Glob. Change, 7: 367-380.

Rahman, M.R. and Lateh, H. (2017). Climate change in Bangladesh: a spatio-temporal analysis and simulation of recent temperature and rainfall data using GIS and time series analysis model. Theor. App. Climatol., 128: 27-41.

Rivington, M. and Koo, J. (2011). Report on the meta-analysis of crop modelling for climatechange and food security survey. CGIAR Program on Climate Change,Agri. and Food Secur., Copenhagen, Denmark.

Sarker, M.A.R., Alam, K. and Gow, J. (2012). Exploring the relationship between climate change and rice yield in Bangladesh: An analysis of time series data. Agri. Syst., 112: 11-16.

Sandhu, S.S., Kaur, P., Gill, K.K. and Bala, A. (2013). Effect of inter and intra seasonal variability in meteorological parameters on rice productivity in central Punjab, $J$. Agrometeorol., 15(2): 147-151.

Vysakh,A., Kumar,B.A. and Subbarao,A.V.M.(2017). Evaluation of CERES-Rice model for the selected rice varieties of Kerala. J. Agrometeorol., 18(1): 120-123.

Yu, W.H., Alam, M., Hassan, A., Khan, A.S., Ruane, A.C., Rosenzweig, C., Major, D.C. and Thurlow, J. (2010). Climate Change Risk and Food Security in Bangladesh. Earth Scan, London. 